\title{
ENSAIOS SOBRE EÇA DE QUEIRÓS NO JORNAL DE LETRAS, ARTES E IDEIAS
}

\section{ESSAYS ABOUT EÇA DE QUEIRÓS IN THE JORNAL DE LETRAS, ARTES E IDEIAS}

https://doi.org/10.46551/2179679320200007

Cristiane NavarreteTolomei Universidade Federal do Maranhão

cntolomei@yahoo.com.br iD 1 ttps://orcid.org/0000-0001-7017-0943

RESUMO: Trata o presente texto de resultado de pesquisa que reuniu os ensaios publicados sobre o autor português Eça de Queirós no Jornal de Letras, Artes e Ideias _JL_, de Lisboa, de 1981 a 2013. Após visitas realizadas à Sala de Materiais Especiais, da Biblioteca Florestan Fernandes, da Faculdade de Filosofia, Letras e Ciências Humanas, da Universidade de São Paulo, encontramos, no recorte temporal escolhido, 33 ensaios acerca do nosso objeto de estudo. Assim, trazemos para este artigo, de forma inédita, a catalogação e análise de quatro ensaios, como amostragem do material, verificando as diretrizes críticas e teóricas utilizados pelos autores das publicações, além de observar como os textos jornalísticos convergiram e/ou divergiram com as críticas queirosianas basilares e referenciais.

PALAVRAS-CHAVE: Eça de Queirós. Jornal de Letras, Artes e Ideias. História e Crítica Literária. Fontes Primárias. Periódicos.

ABSTRACT: This text deals with the result of a research that gathered the essays published on the Portuguese author Eça de Queirós in the Jornal de Letras, Artes e Ideias_JL_, in Lisbon, from 1981 to 2013. After visits to the Sala de Materiais Especiais, from the Florestan Fernandes Library, of the Faculdade de Filosofia, Letras e Ciências Humanas, of the Universidade de São Paulo, we found, in the chosen time frame, 33 essays about our object of study. Thus, we bring to this article, in an unprecedented way, the cataloging and analysis of four essays, as a sample of the material, verifying the critical and theoretical guidelines used by the authors of the publications and observing how the journalistic texts converged and/or diverged with the basic and referential critiques about Eça de Queirós.

KEYWORDS: Eça de Queirós. Jornal de Letras, Artes e ldeias. History and Literary Criticism. Primary Sources. Periodicals. 
Propomos, neste artigo, divulgar o resultado inédito do estudo sistemático das publicações ensaísticas sobre o escritor português Eça de Queirós no periódico de Lisboa denominado Jornal de Letras, Artes e Ideias_JL_, de 1981 a 2013, observando a diversidade dos ensaios para discussão da vida e da obra do autor.

Quanto ao enfoque metodológico, a pesquisa se valeu do método documental e de campo e, como todo levantamento de objeto de estudo em fontes primárias, a reunião do corpus se deu a partir de visitas à Sala de Materiais Especiais da Biblioteca Florestan Fernandes, da Faculdade de Filosofia, Letras e Ciências Humanas, da Universidade de São Paulo que, desde 2005, com a unificação do Serviço de Biblioteca e Documentação, passou a funcionar como um espaço específico para pesquisas a atlas, mapas, materiais diversos (CDs, DVDs, fitas, discos), revistas e jornais. Nesse acervo, chegamos aos seguintes dados: de 1981 a 2013 foram publicados 1127 exemplares do periódico lisboeta, com uma média de 34 páginas, já que os números transitavam entre 24 a 44 páginas, todos consultados no material impresso. Sobre Eça de Queirós, de acordo com o nosso recorte, encontramos 33 ensaios.

Notamos que os ensaios reunidos ou ecoam a crítica queirosiana estabelecida ou argumentam as leituras sobre Eça e sua obra, rompendo limites e construindo novos objetivos de metodologia e análise. Há também os ensaios que abusam do formato opinativo, estabelecendo certas relações equivocadas acerca da obra queirosiana. Em vista disso, este estudo serve como parâmetro, por intermédio da catalogação dos ensaios a respeito de Eça de Queirós no periódico lisboeta, para compreender como abordagens díspares, por vezes antagônicas, revelam e enraízam subsídios sobre o autor português.

Com o objetivo de divulgar as letras, as artes e as ideias produzidas pelos países de língua portuguesa, destacamos o papel do periódico especializado português Jornal de Letras, Artes e Ideias _JL_, que assume essa função de forma brilhante e defende há quase 40 anos os escritores, artistas e pensadores portugueses, brasileiros, cabo-verdianos, moçambicanos, angolanos, guineenses e são tomenses.

O Jornal de Letras, Artes e Ideias surgiu em Lisboa com o seu número 1 no dia 3 de março de 1981, e até hoje cumpre uma missão importante na divulgação, 
com qualidade, de assuntos diversos que transitam entre as artes, as ideias, mas, sobretudo, as letras. No periódico português, encontramos os gêneros jornalísticos "tradicionais" informativos (como a notícia, a entrevista, a reportagem, o perfil ou o destaque) e de opinião (como o editorial, a crônica, o comentário e/ou crítica), mas também alguns gêneros mais específicos do jornalismo cultural (como o ensaio, a resenha, o poema, o conto, a banda desenhada ou a "agenda cultural"). Segundo, Jorge Rivera:

[o jornalismo cultural é uma] zona complexa e heterogênea de meios, gêneros e produtos que abordam com propósitos criativos, críticos, reprodutivos ou de divulgação, os territórios das belas artes e das belas letras, as correntes de pensamento, as ciências sociais e humanas, a chamada cultura popular e muitos outros aspectos que têm a ver com a reprodução, circulação e consumo de bens simbólicos, independentemente da sua origem ou do seu destino ${ }^{1}$.

Nesse sentido, a imprensa cultural caracteriza-se por uma dupla condição - criativa e reprodutiva - presente quer nas revistas, quer nos semanários ou quinzenários especializados, quer nos suplementos culturais dos jornais diários. A dimensão criativa está relacionada à produção artística e intelectual inéditas, enquanto a dimensão reprodutiva diz respeito à divulgação de bens simbólicos de patrimônios tradicionais. Para além da função "informativa" (independentemente de tratar-se da divulgação de bens simbólicos de patrimônios tradicionais ou de produção vanguardistas), o jornalismo cultural assume contornos específicos, podendo atribuírem-Ihe uma tripla função: a) Crítica (associada à sua condição histórica, pois, como vimos, o jornalismo cultural desenvolveu-se paralelamente ao espaço público e trouxe consigo o cunho da crítica, inicialmente literária, estendendo-se depois às demais manifestações da arte e do pensamento e às implicações políticas da sua produção); b) Performativa (a abordagem cultural de qualquer assunto, seja a crítica a um livro ou uma notícia sobre uma peça de teatro, podendo levar os leitores à ação, seja esta a de comprar o livro ou participar no espetáculo em questão); c) Mediadora democrática (o jornalismo cultural nasceu com a função de "mediar o conhecimento", permitindo o acesso

\footnotetext{
${ }^{1}$ RIVERA, 2003, p. 19.
} 
das massas à arte, à literatura e à filosofia, campos até aí exclusivos da elite; por outro lado, jornalismo cultural está historicamente ligado às minorias e às subculturas, podendo dar-Ihes voz). Todavia, embora desejável, esta é uma feição do jornalismo cultural que não temos frequentemente oportunidade de observar, daí a relevância do Jornal de Letras, Artes e Ideias, o qual faz um jornalismo cultural de alta qualidade, voltado para a massa e vinculado a países com culturas diferentes da portuguesa. Na realidade, o JL rompe as barreiras sociais, raciais, econômicas, políticas e culturais para atingir seus leitores no mundo todo.

No Jornal de Letras, Artes e Ideias, o ensaio tem um espaço importante no periódico, aparecendo, concomitantemente, nas três partes do periódico: "Letras", "Artes" e "Ideias". Em relação aos ensaios sobre Eça de Queirós, de 1981 a 2013, estão localizados em duas das três partes do periódico português: 27 ensaios em "Letras" e 6 ensaios em "Ideias”. São textos distribuídos em curtos a longos, que trazem títulos que exigem do leitor uma (re)significação, já que é necessário, em muitos casos, um retomada a discussões teóricas, contextuais e analíticas, já comentadas nos estudos queirosianos anteriores ou que estão em voga, isto é, o leitor dos ensaios do $J L$ precisa recorrer a outras leituras para que ganhe em significados essa nova leitura dos textos ensaísticos do periódico português.

O escritor português José Maria Eça de Queirós (1845-1900) é uma figura que ocupa há muito tempo e de forma ininterrupta o centro da vida cultural lusitana. Sua aparição nos ensaios do $J L$ já era esperada, uma vez que é um dos principais nomes da literatura mundial. Nos 33 anos percorridos, encontramos um número considerável de publicações acerca de Eça, surgindo no JL, por exemplo, crônicas, propagandas sobre livros de e sobre o autor realista, divulgação de eventos, cartas, debates, fotografias, resenhas, entrevistas, sobremaneira, ensaios, etc., sendo, portanto, um jornal de significativo caráter documental.

A presença de Eça no $J L$ é garantia da perenidade do autor, permitindo que nos últimos 30 anos, ele permaneça intrigando leitores e críticos. Desse modo, o periódico lisboeta é um organismo acolhedor dos estudos sobre a vida e obra queirosiana, que não pode ser deixado de lado. Logo, em relação ao exposto, a seguir, um quadro mais detalhado acerca das produções ensaísticas sobre Eça no $J L$ nos 33 anos percorridos: 
Programa de Pós-graduação em Letras/Estudos Literários da Unimontes v.21, n.1, 2020. ISSN: 2179-6793

Quadro 1. Ensaios sobre Eça de Queirós no JL, de 1981 a 2013.

\begin{tabular}{|c|c|c|}
\hline Publicação & $\begin{array}{c}\text { Jornalista/Colaborad } \\
\text { or }\end{array}$ & Título \\
\hline $\begin{array}{l}\text { Ano I no } 7 \text {, de } \\
26 \text { de maio a } \\
8 \text { de junho } \\
\text { de } 1981\end{array}$ & Alfredo Campos Matos & $\begin{array}{l}\text { Eça, Zé Fernandes e o discurso da } \\
\text { cidade }\end{array}$ \\
\hline 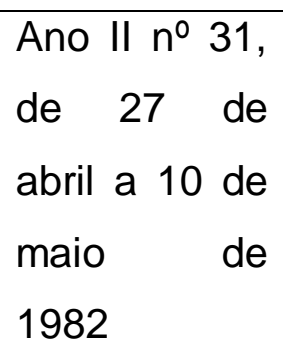 & $\begin{array}{l}\text { Alexandre Pinheiro } \\
\text { Torres }\end{array}$ & $\begin{array}{l}\text { A jacíntica figura, os companheiros de } \\
\text { Belzebú e Eça à lupa de Tomás } \\
\text { Ribeiro Colaço }\end{array}$ \\
\hline $\begin{array}{l}\text { Ano II } n^{0} \text { 78, } \\
\text { de } 3 \text { a } 9 \text { de } \\
\text { janeiro de } \\
1984\end{array}$ & Carlos Reis & Cartas de Eça a Luís de Magalhães \\
\hline $\begin{array}{l}\text { Ano IV no } 89, \\
\text { de } 20 \text { a } 26 \\
\text { de março de } \\
1984\end{array}$ & $\begin{array}{l}\text { Fernando António de } \\
\text { Almeida }\end{array}$ & $\begin{array}{l}\text { De Eça a Pessoa ou a polémica dos } \\
\text { prémios }\end{array}$ \\
\hline $\begin{array}{l}\text { Ano IV } \mathrm{n}^{\circ} \\
117 \text {, de } 2 \text { a } 8 \\
\text { de outubro } \\
\text { de } 1984\end{array}$ & Alfredo Margarido & $\begin{array}{l}\text { Outra maneira de ver o africanista } \\
\text { Gonçalo Mendes Ramires }\end{array}$ \\
\hline $\begin{array}{l}\text { Ano VI } \mathrm{n}^{\circ} \\
232, \\
\text { de } 15 \text { a } 21 \\
\text { de dezembro } \\
\text { de } 1986\end{array}$ & Luiz Fagundes Duarte & O regresso de Eça \\
\hline $\begin{array}{l}\text { Ano VII } \mathrm{n}^{0} \\
267 \text {, de } 17 \text { a } \\
23 \text { de agosto }\end{array}$ & $\begin{array}{l}\text { Manuel Cadafaz de } \\
\text { Matos }\end{array}$ & $\begin{array}{l}\text { Eça de Queiroz e Batalha Reis através } \\
\text { de cartas inéditas }\end{array}$ \\
\hline
\end{tabular}


Programa de Pós-graduação em Letras/Estudos Literários da Unimontes v.21, n.1, 2020. ISSN: 2179-6793

\begin{tabular}{|c|c|c|}
\hline de 1987 & & \\
\hline $\begin{array}{l}\text { Ano VIII } n^{0} \\
338 \text {, de } 27 \\
\text { de dezembro } \\
\text { de } 1988 \text { a } 2 \\
\text { de janeiro de } \\
1989\end{array}$ & $\begin{array}{l}\text { Américo Guerreiro de } \\
\text { Sousa }\end{array}$ & O incesto n’Os Maias \\
\hline $\begin{array}{l}\text { Ano IX } \mathrm{n}^{\circ} \\
374 \text {, de } 5 \text { a } \\
11 \\
\text { setembro de } \\
1989\end{array}$ & Alfredo Campos Matos & Eça de Queiroz lido por António Sérgio \\
\hline $\begin{array}{l}\text { Ano IX } \mathrm{n}^{\circ} \\
374 \text {, de } 5 \text { a } \\
11 \\
\text { setembro de } \\
1989\end{array}$ & $\begin{array}{l}\text { Isabel de Faria e } \\
\text { Albuquerque }\end{array}$ & Três cartas inéditas \\
\hline $\begin{array}{l}\text { Ano } \times \text { no } \\
400 \text {, de } 6 \text { a } \\
12 \text { de março } \\
\text { de } 1990\end{array}$ & Alfredo Campos Matos & Eça, filosofia e personagens \\
\hline $\begin{array}{l}\text { Ano XII } \mathrm{n}^{0} \\
516 \text {, de } 26 \\
\text { de maio a } 2 \\
\text { de junho de } \\
1992\end{array}$ & Alfredo Campos Matos & Releitura de um retrato \\
\hline $\begin{array}{l}\text { Ano XIV } n^{0} \\
618 \text {, de } 22 \\
\text { de junho a } 5 \\
\text { de julho de } \\
1994\end{array}$ & Fernando Venâncio & O enteado \\
\hline Ano $\mathrm{XVI} \mathrm{n}^{\circ}$ & Ana Maria Almeida & Antero admirador de Eça \\
\hline
\end{tabular}




\begin{tabular}{|c|c|c|}
\hline $\begin{array}{l}674 \text {, de } 14 \text { a } \\
27 \text { de agosto } \\
\text { de } 1996\end{array}$ & Martins & \\
\hline $\begin{array}{lll}\text { Ano } & \text { XVII } & \mathrm{n}^{0} \\
710, & \text { de } & 31 \\
\text { de } & \text { dezembro } \\
\text { a } & 13 & \text { de } \\
\text { janeiro } & \text { de } \\
1998 & \end{array}$ & Alfredo Campos Matos & As "iniciações" de Jacinto em Tormes \\
\hline $\begin{array}{l}\text { Ano XIX } \mathrm{n}^{0} \\
749 \text {, de } 16 \text { a } \\
29 \text { de junho } \\
\text { de } 1999\end{array}$ & Carlos Reis & A literatura do futuro \\
\hline 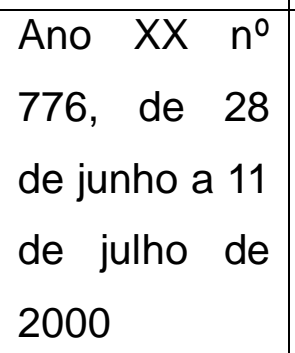 & $\begin{array}{l}\text { Guilherme D'Oliveira } \\
\text { Martins }\end{array}$ & Esse misterioso Fradique Mendes \\
\hline $\begin{array}{l}\text { Ano XX } n^{0} \\
777 \text {, de } 12 \text { a } \\
25 \text { de julho } \\
\text { de } 2000\end{array}$ & $\begin{array}{l}\text { Guilherme D'Oliveira } \\
\text { Martins }\end{array}$ & Peregrinação a Tormes com Jacinto \\
\hline $\begin{array}{l}\text { Ano } X X \text { no } \\
779 \text {, de } 9 \text { a } \\
22 \text { de agosto } \\
\text { de } 2000\end{array}$ & Alfredo Campos Matos & $A$ actualidade de um autor \\
\hline $\begin{array}{l}\text { Ano } X X \text { no } \\
779 \text {, de } 9 \text { a } \\
22 \text { de agosto } \\
\text { de } 2000\end{array}$ & João Medina & Estudo sobre A Relíquia \\
\hline $\begin{array}{l}\text { Ano } \mathrm{XX} \mathrm{n}^{0} \\
779, \text { de } 9 \text { a }\end{array}$ & João Pedro Fernandes & Abençoadas incoerências \\
\hline
\end{tabular}




\begin{tabular}{|c|c|c|}
\hline $\begin{array}{l}22 \text { de agosto } \\
\text { de } 2000\end{array}$ & & \\
\hline 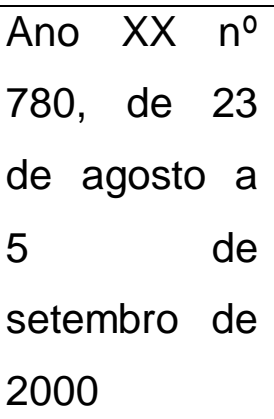 & $\begin{array}{l}\text { Guilherme D'Oliveira } \\
\text { Martins }\end{array}$ & Almanaque de Samarcanda \\
\hline 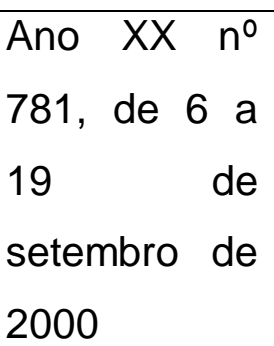 & Carlos Reis & $\begin{array}{l}\text { Os Maias na escola: missão } \\
\text { impossível? }\end{array}$ \\
\hline $\begin{array}{l}\text { Ano XX } \mathrm{n}^{0} \\
786 \text {, de } 15 \text { a } \\
28 \text { de } \\
\text { novembro de } \\
2000\end{array}$ & $\begin{array}{l}\text { Luís Filipe Castro } \\
\text { Mendes }\end{array}$ & $\begin{array}{l}\text { Eça de Queirós e o Brasil: O } \\
\text { sentimento impossível }\end{array}$ \\
\hline $\begin{array}{l}\text { Ano XXII } n^{0} \\
834 \text {, de } 18 \text { a } \\
1 \text { de outubro } \\
\text { de } 2002\end{array}$ & $\begin{array}{l}\text { Guilherme D'Oliveira } \\
\text { Martins }\end{array}$ & O regresso de Fradique Mendes \\
\hline $\begin{array}{l}\text { Ano XXIII no } \\
872 \text {, de } 3 \text { a } \\
16 \text { de março } \\
\text { de } 2004\end{array}$ & $\begin{array}{l}\text { Guilherme D'Oliveira } \\
\text { Martins }\end{array}$ & De Fradique a Branca Dias \\
\hline $\begin{array}{l}\text { Ano XXVI no } \\
943, \text { de } 22 \\
\text { de novembro } \\
\text { a } 5 \text { de } \\
\text { dezembro de } \\
2006\end{array}$ & Carlos Reis & Da biografia à ficção da História \\
\hline
\end{tabular}




\begin{tabular}{|c|c|c|}
\hline $\begin{array}{l}\text { Ano XXVIII } \\
\text { no 987, de } 30 \\
\text { de julho a } 12 \\
\text { de agosto de } \\
2008\end{array}$ & Carlos Reis & João Gomes antes de Fradique \\
\hline $\begin{array}{l}\text { Ano XXVIII } \\
\text { no 987, de } 30 \\
\text { de julho a } 12 \\
\text { de agosto de } \\
2008\end{array}$ & Irene Fialho & $\begin{array}{l}\text { De comboio até Jerusalém pelos } \\
\text { trilhos da memória }\end{array}$ \\
\hline $\begin{array}{l}\text { Ano XXIX no } \\
1005 \text {, de } 8 \text { a } \\
21 \text { de abril } \\
\text { de } 2009\end{array}$ & $\begin{array}{l}\text { Guilherme D'Oliveira } \\
\text { Martins }\end{array}$ & Sobre o último Eça... \\
\hline $\begin{array}{l}\text { Ano XXXIII } \\
n^{\circ} 1116 \text {, de } \\
10 \text { a } 23 \text { de } \\
\text { julho de } 2013\end{array}$ & Carlos Reis & O jovem Eça e A Morte de Diabo \\
\hline $\begin{array}{l}\text { Ano XXXIII } \\
\text { no } 1117 \text {, de } \\
24 \text { de julho a } \\
6 \text { de agosto } \\
\text { de } 2013\end{array}$ & Carlos Reis & Alguns tópicos de uma releitura \\
\hline $\begin{array}{l}\text { Ano XXXIII } \\
\text { no } 1117 \text {, de } \\
24 \text { de julho a } \\
6 \text { de agosto } \\
\text { de } 2013\end{array}$ & $\begin{array}{l}\text { Maria do Rosário } \\
\text { Cunha }\end{array}$ & Para uma edição crítica \\
\hline
\end{tabular}

Fonte: Autora.

De acordo com o quadro, todos os ensaios foram escritos por colaboradores portugueses, em sua maioria, grandes nomes dos estudos 
queirosianos. Os 33 ensaios estão distribuídos, no recorte escolhido, da seguinte forma: na década de 1980, houve 10 publicações; na década de 1990, 6 publicações; e entre 2000 e 2013, 17 publicações. Podemos notar, de antemão, que os ensaios sobre Eça na década de 1990 obtiveram um número menor do que nas demais décadas, já que nenhuma efeméride ocorreu nesse período. Por exemplo, na década de 1980, tivemos o centenário de Os Maias; e no ano 2000, homenagem ao centenário da morte do autor, além das comemorações da publicação de $A$ ilustre casa de Ramires, e em 2001, de A cidade e as serras, motivos que justificam o maior número de ensaios nessas décadas.

De maneira geral, os ensaios trazem reflexões desde a bibliografia ativa e passiva de Eça, biografias, cartas inéditas, métodos de pesquisa da obra queirosiana até debate sobre a edição crítica da obra. À vista disso, o material encontrado contribui, sobremaneira, aos estudos queirosianos por levantar questões centrais sobre Eça para o público geral. Como uma breve amostragem da qualidade dos ensaios e das ideias suscitadas, apresentamos a breve análise dos quatro primeiros ensaios, os quais contribuíram para novas perspectivas ou permanência de leituras críticas já estabelecidas pelos estudiosos do autor.

O primeiro ensaio sobre Eça de Queirós foi publicado na edição de número 7, de 26 de maio a 8 de junho de 1981, na parte de "Letras" do JL, escrito pelo queirosiano português Alfredo Campos Matos, o qual tem uma participação ativa e substancial no periódico por décadas. Ele traz como título "Eça, Zé Fernandes e o discurso da cidade" devido às comemorações dos 80 anos do romance $A$ cidade e as serras, analisando o discurso enraizado por trás da narrativa, assim, questiona o seu leitor: "é o escritor pela cidade ou pelo campo, ou teria andado ele, muito simplesmente, a enganar-nos?"2

No confronto entre o discurso da cidade e do campo, Campos Matos defende o posicionamento favorável de Eça, por meio do narrador Zé Fernandes, ao discurso do campo. Em outras palavras, o ensaísta aponta para as artimanhas do escritor realista para que público e crítica entendessem o discurso da cidade como o mais relevante. Recorrendo à acalentada leitura do brasileiro Antonio Candido, no Brasil, em 1945, e republicada em 2000, a respeito do romance $A$

${ }^{2}$ MATOS, JL, n.7, 1981, p. 16. 
cidade e as serras:

[...] observada no conjunto, mesmo de maneira superficial, a obra de Eça de Queirós se apresenta em grande parte como diálogo entre campo e cidade - ora predominando a nota urbana, ora fazendo-se ouvir mais forte a nota rural. Numa sociedade europeia do século XIX, como a portuguesa, cidade deveria significar vida moderna, intercâmbios sociais intensos, participação na civilização capitalista do Ocidente. Campo significaria tradicionalismo, economia agrária, sentido paternal nas relações entre as classes ${ }^{3}$.

De acordo com o excerto, podemos observar, então, que o discurso do campo significaria a Eça de Queirós um recuo ideológico em relação aos primeiros romances, leitura reconhecida pela crítica queirosiana em geral. Entretanto, no ensaio do $J L$, Campos Matos alerta para a "prosa sedutora" de Eça, possibilitando ao leitor interpretar que, na realidade, o narrador, em vez de defender o campo, defende a cidade:

Quem poderá sustentar que Eça acreditaria nessa tese superficial que retira à cidade - uma das maiores criações do homem - a sua virtude essencial, que é precisamente a de criar inteligência, cultura e progresso? ${ }^{4}$.

A interpretação de Campos Matos, como já foi apontada, rompe com a visão de grande parte dos queirosianos, ao caracterizar o último Eça como um apologista de um Portugal tradicional, encerrado em princípios nacionais; um autor conformista e de reconciliação com a pátria; um autor que traiu as ideias revolucionárias da chamada "Primeira Fase" de sua obra propriamente realista.

Importante ressaltar que Campos Matos não lança essa dúvida entre acadêmicos, mas a um público geral, que passa a ser incentivado a ler ou reler $A$ cidade $e$ as serras com um olhar mais desconfiado diante do jogo entre o discurso da cidade e do campo na voz de Zé Fernandes.

Na edição de número 31, de 27 de abril a 10 de maio de 1982, na parte de "Letras" do JL, Alexandre Pinheiro Torres com o ensaio denominado "A jacíntica figura, os companheiros de Belzebú e Eça à lupa de Tomás Ribeiro Colaço"

${ }^{3}$ CANDIDO, 2000, p. 31.

${ }^{4}$ MATOS, JL, n.7, 1981, p. 16. 
retoma o debate literário, via ficção, iniciado em A Folha de Parra, de 1932, romance escrito por Tomás Ribeiro Colaço, no qual põe em causa as estruturas narrativas tradicionais.

Primeiro, Alexandre Pinheiro Torres afirma erroneamente que essa crítica não estava incluída na "Bibliografia Passiva de Eça de Queiroz", de Ernesto Guerra da Cal (1976): ${ }^{5}$

Passada de novo à peneira $A$ Folha de Parra acorri aos grossos volumes da "Bibliografia Passiva de Eça de Queirós" para averiguar se Guerra Da Cal o incluiu no imenso repositório. Nem sombras. Uma das mais brilhantes especulações críticas sobre o autor de Os Maias tinha caído no buraco! ${ }^{6}$.

Contudo, em pesquisa realizada na acalentada Bibliografia, a referência foi encontrada entre os artigos sobre a obra de Eça.

Segundo, Pinheiro Torres denuncia o cânone estabelecido para a literatura portuguesa, ressaltando que há nomes das letras que caíram no esquecimento tal como o de Tomás Ribeiro Colaço: "E Ribeiro Colaço, o brilhante espírito, revolverse-ia de gozo no Céu dos Escritores Esquecidos porque no Inferno se encontram os Continuamente Lembrados"7. Na verdade, notamos um certo ressentimento nas linhas de Torres, pois ele não faz somente uma crítica ao cânone literário português, mas também realiza um ataque a Eça. Assim, valendo-se das ideias de Colaço, Torres concebe o romance $A$ cidade e as serras como mal estruturado, no qual o protagonista Jacinto não poderia ser a representação nem da cidade, nem do campo.

Jacinto não se encontrava em condições biológicas, logo psicológicas, logo ontológicas de ter a alma de um supercivilizado. Pelo menos, essa alma não a poderia ter herdado. Tê-la-ia adquirido? Nem pensar porque para se ser supercivilizado é preciso ser-se superinteligente e Jacinto nem inteligente era. Nem sequer digerira a Civilização [...] Mais ainda: a Cidade fazia um mal verdadeiramente infernal a Jacinto [...] que the teria sucedido na Serra, se em vez de comida suculenta e saudável, Ihe esturrassem a canja, o frango estivesse córneo ou a água lhe impingisse o tifo? Donde se conclui que se o "meu Príncipe"

5GUERRA DA CAL, 1976.

6 TORRES, JL, n. 31, 1982, p. 16.

7 TORRES, JL, n. 31, 1982, p. 16. 
ganha apetite, se na Serra se descorcova e fica corado como uma moçoila minhota é porque Eça, por sua vez, raciocinou pessimamente. Então na cidade não há canja que tenha suco? Não haverá nela, vindos dos arrabaldes, frangos tenros? Então se um supercivilizado sabe acumular livros e garrafas de vinho porque não sabe acumular os ingredientes com que se faz uma canja? ${ }^{8}$.

Além disso, Pinheiro Torres é categórico ao afirmar que há incongruências no romance, uma vez que Eça canta o campo, porém se mantém próximo à civilização citadina:

E onde é que, afinal, Eça ou Jacinto, acabam por exaltar a Cidade? Porque para um ou outro o amor do Campo inconciliável com uma barba escanhoada. Um supercivilizado se o é, é-o sempre, esteja onde estiver, porque continuará superinteligente (TORRES, JL, n. 31, 1982, p. 16).

Encerrando o ensaio, reafirmando a sua concepção de que há muitos autores e livros esquecidos no "Paraíso" mais interessantes e relevantes do que caminhar e referendar as mesmas obras, consideradas acima de todas.

Em vista disso, notamos que Alexandre Pinheiro Torres faz algumas denúncias, todas, a nosso ver, com um teor exageradamente parcial e opinativo. Faz críticas ao estudo de Guerra da Cal de forma inconsequente, sem uma verificação prévia e detalhada, passando uma informação errada ao público leitor do $J L$, além de tirar a credibilidade da Bibliografia. Em seguida, reproduzindo a ideia de Tomás Ribeiro Colaço, insere $A$ cidade $e$ as serras entre os grandes equívocos do cânone português.

Como é sabido, Jacinto, aristocrata hiper-civilizado, defende a ideia de que "o homem só é superiormente feliz quando é superiormente civilizado", desembocando num pessimismo mórbido e num tédio sufocante, resultante de um excesso de cultura, saber e da acumulação de bens materiais, consequência do progresso da civilização pelo qual ele se deixou deslumbrar. A partida de Jacinto para as serras, permitiu-Ihe assumir outra posição perante a letargia que era alimentada pela cidade. Transita, assim, de um estado de "ignorância", de não consciência de si próprio, não pela falta de informação, mas sim pelo seu inverso,

8 TORRES, JL, n. 31, 1982, p. 16. 
pelo seu excesso, para um estado de conhecimento associado a uma seleção de informações.

Na edição de número 78, de 3 a 9 de janeiro de 1984, na parte de "Letras", do $J L$, Carlos Reis escreve um ensaio introdutório denominado "Cartas de Eça a Luís de Magalhães", anunciando e analisando brevemente cartas inéditas de Eça de Queirós a Luís de Magalhães. São cinco cartas que se encontravam no espólio de Magalhães e que dali por diante ficariam em exposição na Biblioteca Nacional de Lisboa.

Luís de Magalhães foi um grande destinatário de Eça ao lado de Ramalho Ortigão, Oliveira Martins, Jaime Batalha Reis e D. Emília de Castro. Na grande parte de correspondência trocada entre Eça e Magalhães o assunto era publicação de textos queirosianos na Revista de Portugal, periódico no qual Magalhães era editor, tratando especificamente sobre prazos de entrega e correções dos textos. Nas cinco cartas trazidas por Carlos Reis ao leitor do JL, notamos que falam sobre a contribuição de Eça de Queirós não ao periódico, mas para o In Memoriam de Antero de Quental, em ocasião da morte do poeta, livro destinado a recolher o testemunho de intelectuais contemporâneos de Antero.

Registe-se, por último, que estas cartas constituem como que o preâmbulo que conduz a uma releitura do texto a que se referem e só por isso já valeria a pena revelá-las. De facto, "Um Génio que era um Santo" faculta-nos, para além das imperecíveis e sempre fascinantes qualidades patenteadas pela prosa queirosiana, um retrato de geração com indisfarçáveis matizes autobiográficos. E isto é tanto mais importante quanto é certo serem muito parcas as revelações queirosianas de incidência autobiográfica. A ponto de ter ficado inédito, até depois da morte de Eça, o texto "O Francesismo", quer dizer, aquele em que essas revelações são mais directas e transparentes.

Em "Um Génio que era um Santo" não é, pois, apenas Antero que está em causa; Antero e a sua ética, a sua filosofia, a sua estatura cultural, de par com um percurso biográfico atravessado por angústias e dúvidas de difícil pacificação. Para além disso, é também o sugestivo retrato da "encantada e quase fantástica Coimbra" de princípios da década de sessenta, onde germinou e estalou a "Questão Coimbrã", onde se lançaram raízes de amizade e laços de solidariedade cultural que a chamada Geração de 70 tentaria fazer frutificar - sempre sob a égide de Antero. E é ainda, a par de tudo isso, a sentida emoção com que Eça recorda um amigo inesquecível - como ele diz, "alguém, filho querido de Deus, que muito padeceu porque muito compreendeu,e que, simples entre os simples, pondo a sua vasta alma em curtos 
Nas cartas inéditas publicadas no $J L$, Carlos Reis observa que Eça trazia uma preocupação constante em relação a sua escrita, uma vez que o autor realista é conhecido por suas diversas intervenções nos originais. Nessas cartas, Eça solicita ansiosamente a Luís de Magalhães as provas tipográficas de seu texto antes da publicação:

O trabalho sobre as provas (ou sobre versões publicadas anteriormente; ou sobre manuscritos abandonados; ou sobre textos alheios) reflecte um processo de escrita peculiar, ainda não suficientemente estudado em Eça, e que provisoriamente pode see designado como de intertextualidade progressiva. De certa forma, o horror do vazio textual, o pânico diante da página branca sentido por tantos escritores, era compensado, em Eça, por esse processo de constante superação qualitativa de uma versão precedente - superação aparentemente facilitada quando o diálogo intertextual se instituía com um texto já em letra de forma (REIS, JL, n. 78, 1984, p. 4).

Eça é conhecido pela constante "reescritura" de seus textos até alcançar o que para ele seria a "Edição definitiva", isto é, o autor fazia intervenções estruturais e semântico-pragmáticas que iam além da mera revisão estilística. $O$ caso mais famoso é do romance $O$ crime do Padre Amaro, que ganhou três versões: 1874, 1876 e 1880.

Na edição número 89, de 20 a 26 de março de 1984, na parte de "Letras", do JL, Fernando Antônio de Almeida escreve o ensaio "De Eça a Pessoa ou a polémica dos prémios", realizando algumas considerações sobre os concursos literários em Portugal e as injustiças que ocorreram em muitos deles. Almeida realiza um breve percurso sobre as premiações mais polêmicas, destacando os prêmios envolvendo A Relíquia, de Eça de Queirós, e Mensagem, de Fernando Pessoa.

Em 1887, Eça de Queirós concorreu com A Relíquia ao "Prêmio D. Luís da Academia Real das Ciências", perdendo a favor de Henrique Lopes de Mendonça com a obra O Duque de Viseu. Em 1935, Fernando Pessoa participou do "Prêmio

\footnotetext{
${ }^{9}$ REIS, JL, n. 78, 1984, p. 4.
} 
Antero de Quental" com o seu livro Mensagem e essa premiação, logo no seu início de existência, ficou marcada por um incidente, que, contra a vontade de António Ferro, Mensagem foi relegada para a "segunda categoria" (poema de poesia solta), alegando-se que tinha menos de 100 páginas, sendo o prêmio de "primeira categoria" atribuído à obra $A$ Romaria, da autoria de Manuel Joaquim Reis Ventura, que naquela época assinava como Vasco Reis. António Ferro resolveu então elevar o prêmio atribuído à segunda categoria, que era de mil escudos, para um valor igual ao da primeira, de cinco mil escudos.

Em relação a Eça de Queirós, Fernando Antônio de Almeida traz a lume a antiga quimera entre Eça e Pinheiro Chagas tendo como pano de fundo a premiação:

O prémio é atribuído a Henrique Lopes de Mendonça. Em nome do júri, pronuncia-se e explica-se o seu relator, Manuel Pinheiro Chagas. Cumprimentador, abre com respeitoso elogio a Eça, que qualifica "um dos homens mais ilustres, e mais justamente ilustres da literatura portuguesa de hoje". Só que Eça fracassou com A Relíquia. Quê? "O beato e devasso Teodorico, sonhando, a imaginar um drama grandioso e pungente como a condenação e sacrifício de Cristo?" "Com grande surpresa nossa, vemos aquele adorador de santinhos e frequentador das ruas suspeitas de Lisboa sonhando que vê a Paixão de Cristo em todo o seu grandioso aspecto histórico. Mal se pode imaginar o disparatado efeito que produz este contraste; e pior ainda é ainda quando o autor se lembra de súbito que é o seu protagonista que está sonhando e introduz nas cenas mais belas uma nota que arrepia uma desafinação flagrante - Teodorico a sonhar que acende um cigarro no meio da agitação que produz Jerusalém a notícia da morte de Cristo!"10.

Obviamente, como é sabido, Eça não gostou do resultado do concurso, no qual não recebera nenhum voto, muito menos as palavras proferidas por Pinheiro Chagas no momento da entrega do prêmio ao primeiro colocado.

O crítico brasileiro Álvaro Lins em seu estudo História Literária de Eça de Queiroz, de 1939, retratou o episódio de Pinheiro Chagas com indignação, refutando a hipótese de que o personagem Teodorico fosse tratado como um "pateta" e um "devasso" e que não teria repertório intelectual para sonhar com o episódio da Paixão de Cristo. Nesse ponto, Lins ressalta que Chagas usara um método crítico inadequado, pois ele portara-se "como um crítico realista",

10 ALMEIDA, JL, n. 89, 1984, p. 7. 
enquanto Eça estava "no domínio da fantasia"11. Isto é, Lins resume o assunto, afirmando que Pinheiro Chagas ficara estarrecido com "o controle entre o indivíduo que sonhou e o sonho que lhe é atribuído"12, e que ele não conseguira perceber que o sonho de Teodorico fora o resultado da formação inicial do personagem, voltada aos preceitos religiosos. Em outras palavras, o que Lins defende é um sonho criado por uma pessoa com uma forte educação religiosa, que mais tarde se tornara um capitalista e que, ao transitar por estes dois universos díspares, sonha o que sua vivência propicia ${ }^{13}$.

$\mathrm{Na}$ realidade, o JL traz um evento específico entre as discordâncias de Eça e Chagas, quando eles já carregavam certos incômodos, desde a "Questão Coimbrã", as "Conferências do Casino" e o Parlamento.

Por fim, nesta breve amostragem da recepção ensaística de Eça de Queirós no Jornal de Letras, Artes e Ideias (1981-2013), de Lisboa, foi possível observar a densidade dos debates, os quais dialogavam e/ou discordavam com crítica queirosiana estabelecida. Mesmo com alguns equívocos, os quatro ensaios apresentaram ao leitor do jornal um debate que não saía dos muros acadêmicos.

Ademais, a investigação documental foi fundamental para determinar como o JL contribui para a divulgação, com qualidade, da produção cultural e literária de Portugal e do estrangeiro, uma vez que, durante a pesquisa às páginas do jornal, foi possível entrar em contato com textos riquíssimos acerca de escritores portugueses, africanos e brasileiros que estão à espera de novos estudos.

Sobre Eça de Queirós, os ensaios ganham status de documento, uma vez que podem ser instrumentalizados pelos estudiosos para melhor compreender ou questionar a vida e a obra de um dos principais escritores do mundo, que incessantemente é assunto nos periódicos culturais. Logo, a importância das pesquisas desenvolvidas em fontes primárias, tais como os periódicos.

\section{Documento}

JORNAL DE LETRAS, ARTES E IDEIAS. Lisboa. 1981-2013.

\footnotetext{
${ }^{11}$ LINS, 1939, p. 139.

12 LINS, 1939, p. 143-144.

13TOLOMEI, 2014.
} 


\section{Referências}

CANDIDO, Antonio. Eça de Queirós: entre o campo e a cidade. In: Tese e antítese. 4. ed. São Paulo: T. A. Queiroz, 2000, p. 29-56.

GUERRA DA CAL, Ernesto. Língua e estilo de Eça de Queiroz. 8. ed. São Paulo: EDUSP/ Rio de Janeiro: Tempo Brasileiro, 1969.

. Lengua y estilo de Eça de Queiroz. Apéndice. Bibliografía Queirociana Sistemática y Anotada e Iconografía Artística del Hombre y la Obra. Acta Universitatis Conimbrigensis, 1975.

LINS, Álvaro. História literária de Eça de Queiroz. Rio de Janeiro: José Olympio, 1939.

RIVERA, Jorge B. El periodismo cultural. Buenos Aires: Paidós, 2003.

TOLOMEI, Cristiane Navarrete. A recepção de Eça de Queirós no Brasil: leituras do século XX. São Paulo: Scortecci, 2014.

Cristiane NavarreteTolomei é Professora adjunto III de Literaturas de Língua Portuguesa sob o regime de Dedicação Exclusiva, do Centro de Ciências, Educação e Linguagens, da Universidade Federal do Maranhão (UFMA). Docente permanente do Programa de Pós-graduação em Letras (PGLB/UFMA) e do Programa de Pós-graduação em Cultura e Sociedade (PGCult/UFMA).

Recebido em 08 de abril de 2020. Aprovado em 01 de maio de 2020. 